\title{
Reliability of Orthodontic Miniscrews: Bending and Maximum Load of Different Ti-6Al-4V Titanium and Stainless Steel Temporary Anchorage Devices (TADs)
}

\author{
Andrea Scribante 1,*, Mona A Montasser ${ }^{2}$, Eman Saad Radwan 2, Paola Gandini 1, Maria \\ Francesca Sfondrini ${ }^{1}$ \\ 1 Unit of Orthodontics and Paediatric Dentistry - Section of Dentistry - Department of Clinical, Surgical, \\ Diagnostic and Paediatric Sciences, University of Pavia, Pavia, Italy \\ 2 Orthodontic Department, Faculty of Dentistry, Mansoura University, Mansoura, Egypt. \\ * Correspondence: andrea.scribante@unipv.it; Tel.: +39-0382-516223
}

Received: 16 April 2018; Accepted: 4 May 2018; Published: 14 May 2018

\begin{abstract}
Temporary anchorage devices (TADs) have been introduced in orthodontic clinical practice in order to allow tooth movements avoiding side effects in the position of adjacent teeth. Miniscrews are available on the market with different diameters and materials. Accordingly, the purpose of the present report was to measure and compare the forces to bend and fracture different mini implants. Ti-6Al-4V Titanium and stainless steel TADs of different manufacturers (Spider Screw - HDC; Mini implants - Leone; Benefit - Orteam; Storm - Kristal) were evaluated. Two different diameters $(1.5 \mathrm{~mm}$ and $2.0 \mathrm{~mm})$ were tested. Ten unused specimen for each group were blocked in an Instron Universal Testing Machine and a shear load was applied at the neck of the screws. The force to bend the mini implant was measured at $0.1 \mathrm{~mm}$ and $0.2 \mathrm{~mm}$ deflections. Moreover the maximum load before screw fracture was recorded. Data were submitted to statistical analysis. 2.0 TADs showed significantly higher forces than $1.5 \mathrm{~mm}$ screws both at $0.1 \mathrm{~mm}$ and 0.2 $\mathrm{mm}$ deflections and at maximum load. Moreover, no significant differences were reported between titanium and stainless steel mini implants for equal diameter
\end{abstract}

Keywords: anchorage; bend; dentistry; fracture; implant; load; miniscrew; orthodontics; shear

\section{Introduction}

During orthodontic treatment excessive forces have been associated with undesirable reactions and side effects, including bone hyalinization, root resorption, pain, patient discomfort, and anchorage loss [1]. Orthodontic mini implants have been introduced as they allow skeletal anchorage for dental movements, thus decreasing the side effects of anchorage loss. Moreover they permit the management of different orofacial deformities [2]. Several reports showed the use of miniscrews for space management [3], intrusion [4], extrusion [5], retraction of anterior teeth [6], crossbite correction [7] and sliding mechanics [8]. Moreover the use of temporary anchorage devices (TADs) has been reported also for non-conventional purposes, as stabilization for facemask protraction [9], fracture management [10], palatal skeletal expanders [11], and provisional miniscrew-supported pontics [12].

Different lengths (usually $5 \mathrm{~mm}$ to $10 \mathrm{~mm}$ ) and diameters (ranging usually from $1.2 \mathrm{~mm}$ to 2.5 $\mathrm{mm}$ ) are present in the market for orthodontic miniscrews. Generally, larger diameter screws provide greater anchorage forces than smaller diameters [13] and present lower fracture risk under torque loads [14]. On the other hand, miniscrews with a smaller diameter are more easily inserted in narrow spaces with lower risk of radicular damage [15]. The TADs that are most frequently employed in clinical practice usually present a diameter of $1.5 \mathrm{~mm}[16]$. 
Generally manufacturers supply titanium mini implants, but also stainless steel miniscrews are present on the market [17]. In fact, for these devices the osseointegration is not needed as for conventional dental implants, because mechanical retention is the determining factor for primary stability of TADs [18].

The major clinical unwanted adverse event is the fracture of the miniscrew, which imply surgical removal of the broken part [19]. Orthodontic miniscrews have been tested extensively in vitro, and many mechanical parameters have been investigated in order to evaluate factors related with increased fracture risk. Plastic deformation [20], insertion [21] and removal torque [22] have been evaluated.

The knowledge of initial bending and maximum load of different mini implants could help clinicians during the choice of screw material and diameter. Today there are no studies that evaluated bending and fracture forces of different miniscrews under tangential load. Moreover, there are no reports that evaluated stainless steel versus titanium mini implants.

Therefore, the purpose of the present investigation was to measure and compare forces to bend $(0.1 \mathrm{~mm}$ and $0.2 \mathrm{~mm})$ and to fracture both titanium and stainless steel TADs of two different diameters $(1.5 \mathrm{~mm}$ and $2.0 \mathrm{~mm})$ under shear load. The null hypothesis of the study was that there is no significant difference among the various groups tested.

\section{Materials and Methods}

In the present investigation different Ti-6Al-4V titanium and stainless steel orthodontic miniscrews were evaluated (Figure 1).
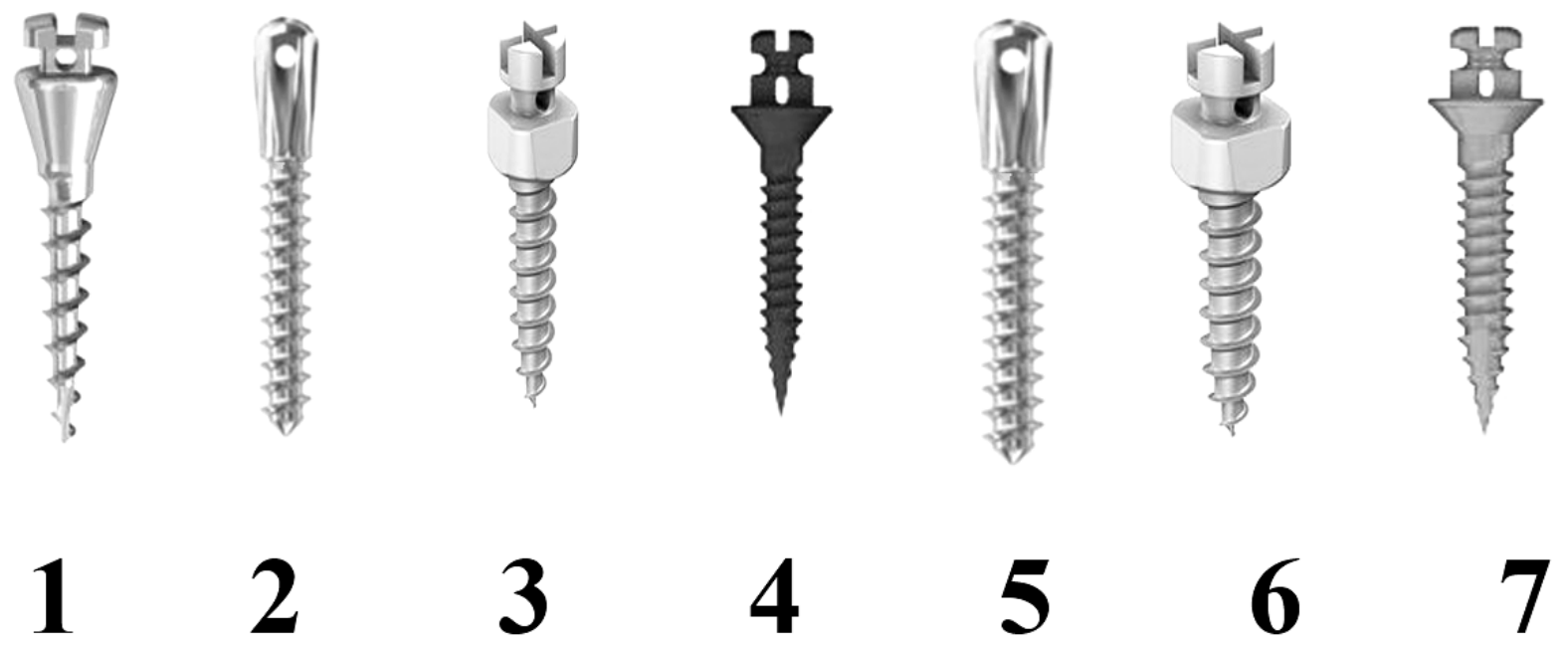

Figure 1. Miniscrews with different diameters tested in the present investigation. 1: $1.5 \mathrm{~mm} \mathrm{HDC}-2$ : $1.5 \mathrm{~mm}$ Leone - 3: $1.5 \mathrm{~mm}$ Orteam - 4: $1.5 \mathrm{~mm}$ Kristal - 5: $2.0 \mathrm{~mm}$ Leone - 6: $2.0 \mathrm{~mm}$ Orteam - 7: 2.0 mm Kristal.

Seven different screws were tested (Table 1): $1.5 \mathrm{~mm}$ (Spider Screw, HDC, Sarcedo, Italy); 1.5 $\mathrm{mm}$ (Mini implants, Leone, Sesto Fiorentino, Italy); $1.5 \mathrm{~mm}$ (Benefit, Orteam, Milano, Italy); $1.5 \mathrm{~mm}$ (Storm; Kristal, Trezzano Sul Naviglio, Italy); $2.0 \mathrm{~mm}$ (Mini implants, Leone, Sesto Fiorentino, Italy); $2.0 \mathrm{~mm}$ (Benefit, Orteam, Milano, Italy); $2.0 \mathrm{~mm}$ (Storm; Kristal, Trezzano Sul Naviglio, Italy). 
Table 1. Materials tested.

\begin{tabular}{cccccc}
\hline Name & Manufacturer & Diameter & Length & Material & $\mathbf{n}$ \\
\hline Spider Screw & HDC & $1.5 \mathrm{~mm}$ & $10 \mathrm{~mm}$ & Titanium Ti-6Al-4V (Grade 5) & 10 \\
Mini Implants & Leone & $1.5 \mathrm{~mm}$ & $10 \mathrm{~mm}$ & Stainless Steel & 10 \\
Benefit & Orteam & $1.5 \mathrm{~mm}$ & $11 \mathrm{~mm}$ & Titanium Ti-6Al-4V (Grade 5) & 10 \\
Storm & Kristal & $1.5 \mathrm{~mm}$ & $10 \mathrm{~mm}$ & Titanium Ti-6Al-4V (Grade 5) & 10 \\
Mini Implants & Leone & $2.0 \mathrm{~mm}$ & $10 \mathrm{~mm}$ & Stainless Steel & 10 \\
Benefit & Orteam & $2.0 \mathrm{~mm}$ & $11 \mathrm{~mm}$ & Titanium Ti-6Al-4V (Grade 5) & 10 \\
Storm & Kristal & $2.0 \mathrm{~mm}$ & $10 \mathrm{~mm}$ & Titanium Ti-6Al-4V (Grade 5) & 10 \\
\hline
\end{tabular}

For each screw 10 different new specimens were tested with a Universal Testing Machine (Instron, Norwood, MA, USA). Each mini implant was blocked in the lower jaw of the machine. The head (between endo osseous thread and trans mucosal collar) was exposed to tangential load (Figure 2) with a $1 \mathrm{~mm} / \mathrm{min}$ crosshead speed [23,24].

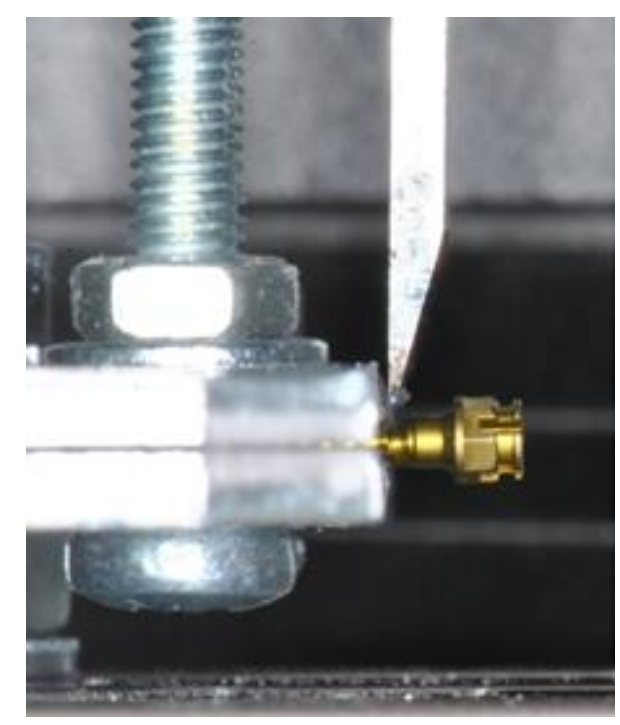

Figure 2. Photograph of the loading test set-up.

Bending force was measured at $0.1 \mathrm{~mm}$ (Groups 1 to 7 ) and $0.2 \mathrm{~mm}$ (Groups 8 to 14) deflections. Moreover the maximum load before screw fracture was recorded (Groups 15 to 21). Load values were reported in newton $[25,26]$.

Statistical analysis was performed with a computer software ( $R$ version 3.1.3, $R$ Development Core Team, R Foundation for Statistical Computing, Wien, Austria). Mean, standard deviation, minimum, median, and maximum were chosen for descriptive statistics and were calculated for the 21 groups. Kolmogorov-Smirnov test assessed Gaussian data distribution. ANOVA (Analysis of variance) and Tukey tests were applied both for $\mathrm{N}$ and MPa data. Significance was predetermined at $P<0.05$ for all statistical tests.

\section{Results}

Table 2 reports descriptive statistics of the load values $(\mathrm{N})$ recorded in the 21 groups, including mean, standard deviation, minimum, median and maximum. 
Table 2. Descriptive statistics of maximum force values $(\mathrm{N})$ of the 21 groups tested (each group consisted of 10 specimens).

\begin{tabular}{ccccccccc}
\hline Group & Diameter & Deflection & Mean & SD & Min & Mdn & Max & Tukey* \\
\hline 1 & $1.5 \mathrm{~mm}$ & $0.1 \mathrm{~mm}$ & 33.28 & 2.92 & 29.28 & 34.16 & 36.86 & $\mathrm{~A}$ \\
2 & $1.5 \mathrm{~mm}$ & $0.1 \mathrm{~mm}$ & 34.69 & 9.50 & 21.13 & 33.38 & 53.70 & $\mathrm{~A}$ \\
3 & $1.5 \mathrm{~mm}$ & $0.1 \mathrm{~mm}$ & 31.53 & 3.86 & 24.34 & 31.81 & 36.21 & $\mathrm{~A}$ \\
4 & $1.5 \mathrm{~mm}$ & $0.1 \mathrm{~mm}$ & 36.38 & 7.01 & 27.67 & 36.00 & 48.65 & $\mathrm{~A}$ \\
5 & $2.0 \mathrm{~mm}$ & $0.1 \mathrm{~mm}$ & 58.00 & 7.17 & 43.45 & 57.99 & 70.73 & $\mathrm{~B}$ \\
6 & $2.0 \mathrm{~mm}$ & $0.1 \mathrm{~mm}$ & 53.07 & 2.92 & 48.84 & 52.71 & 58.16 & $\mathrm{~B}$ \\
7 & $2.0 \mathrm{~mm}$ & $0.1 \mathrm{~mm}$ & 55.21 & 8.58 & 38.58 & 53.63 & 69.32 & $\mathrm{~B}$ \\
8 & $1.5 \mathrm{~mm}$ & $0.2 \mathrm{~mm}$ & 66.57 & 5.85 & 58.56 & 68.32 & 73.73 & $\mathrm{~B}$ \\
9 & $1.5 \mathrm{~mm}$ & $0.2 \mathrm{~mm}$ & 64.71 & 17.71 & 39.48 & 62.29 & 100.42 & $\mathrm{~B}$ \\
10 & $1.5 \mathrm{~mm}$ & $0.2 \mathrm{~mm}$ & 63.05 & 7.72 & 48.68 & 63.62 & 72.42 & $\mathrm{~B}$ \\
11 & $1.5 \mathrm{~mm}$ & $0.2 \mathrm{~mm}$ & 67.87 & 13.06 & 51.66 & 67.19 & 90.44 & $\mathrm{~B}$ \\
12 & $2.0 \mathrm{~mm}$ & $0.2 \mathrm{~mm}$ & 116.00 & 14.34 & 86.91 & 115.98 & 141.46 & $\mathrm{C}$ \\
13 & $2.0 \mathrm{~mm}$ & $0.2 \mathrm{~mm}$ & 106.15 & 5.84 & 97.68 & 105.41 & 116.31 & $\mathrm{C}$ \\
14 & $2.0 \mathrm{~mm}$ & $0.2 \mathrm{~mm}$ & 110.43 & 17.16 & 77.16 & 107.26 & 138.64 & $\mathrm{C}$ \\
15 & $1.5 \mathrm{~mm}$ & Maximum load & 428.03 & 24.29 & 393.61 & 424.80 & 468.61 & $\mathrm{D}$ \\
16 & $1.5 \mathrm{~mm}$ & Maximum load & 481.60 & 133.40 & 300.08 & 462.41 & 773.25 & $\mathrm{D}$ \\
17 & $1.5 \mathrm{~mm}$ & Maximum load & 405.89 & 45.53 & 306.68 & 408.58 & 464.25 & $\mathrm{D}$ \\
18 & $1.5 \mathrm{~mm}$ & Maximum load & 505.67 & 99.29 & 387.43 & 503.65 & 642.12 & $\mathrm{D}$ \\
19 & $2.0 \mathrm{~mm}$ & Maximum load & 747.16 & 90.98 & 573.60 & 739.06 & 919.52 & $\mathrm{E}$ \\
20 & $2.0 \mathrm{~mm}$ & Maximum load & 685.03 & 55.53 & 622.47 & 657.79 & 768.21 & $\mathrm{E}$ \\
21 & $2.0 \mathrm{~mm}$ & Maximum load & 711.78 & 106.73 & 462.97 & 717.64 & 873.41 & $\mathrm{E}$ \\
\hline
\end{tabular}

*: Mean with same letters are not significantly different

ANOVA showed the presence of significant differences among groups $(P<0.001)$. Tukey test used as post hoc reported that, both at $0.1 \mathrm{~mm}$ and at $0.2 \mathrm{~mm}$ deflections, no significant differences were detected among $1.5 \mathrm{~mm}$ diameter miniscrews (groups 1 to 4 and 8 to 11$)(P>0.05)$. Significantly higher forces $(P<0.05)$ were reported for $2.0 \mathrm{~mm}$ diameter TADs (groups 5 to 7 and 12 to 14), that showed no significant differences among them $(P>0.05)$ (Figures 3 and 4$)$.

Similar results were reported at maximum load before screw fracture (Figure 5 - groups 15 to 21).

\section{$0.1 \mathrm{~mm}$ Deflection}

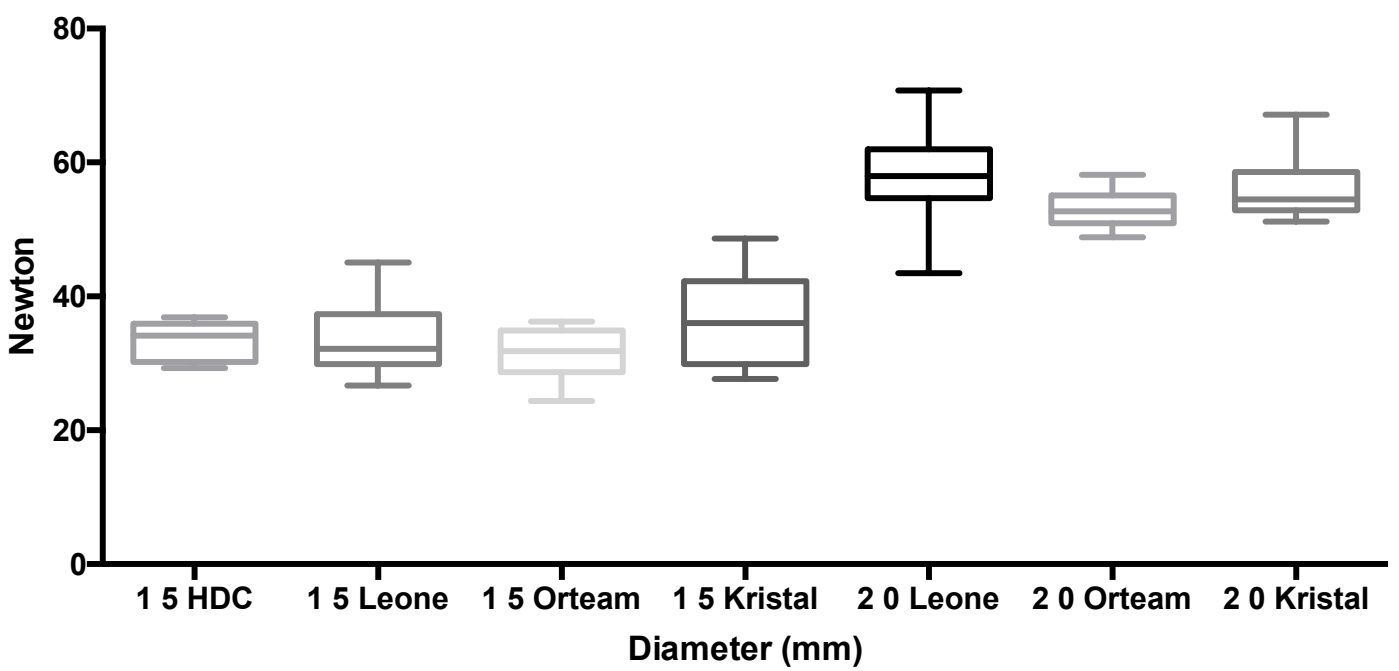

Figure 3. Box plot of groups tested at $0.1 \mathrm{~mm}$ deflection $(\mathrm{N})$. 


\section{$0.2 \mathrm{~mm}$ Deflection}

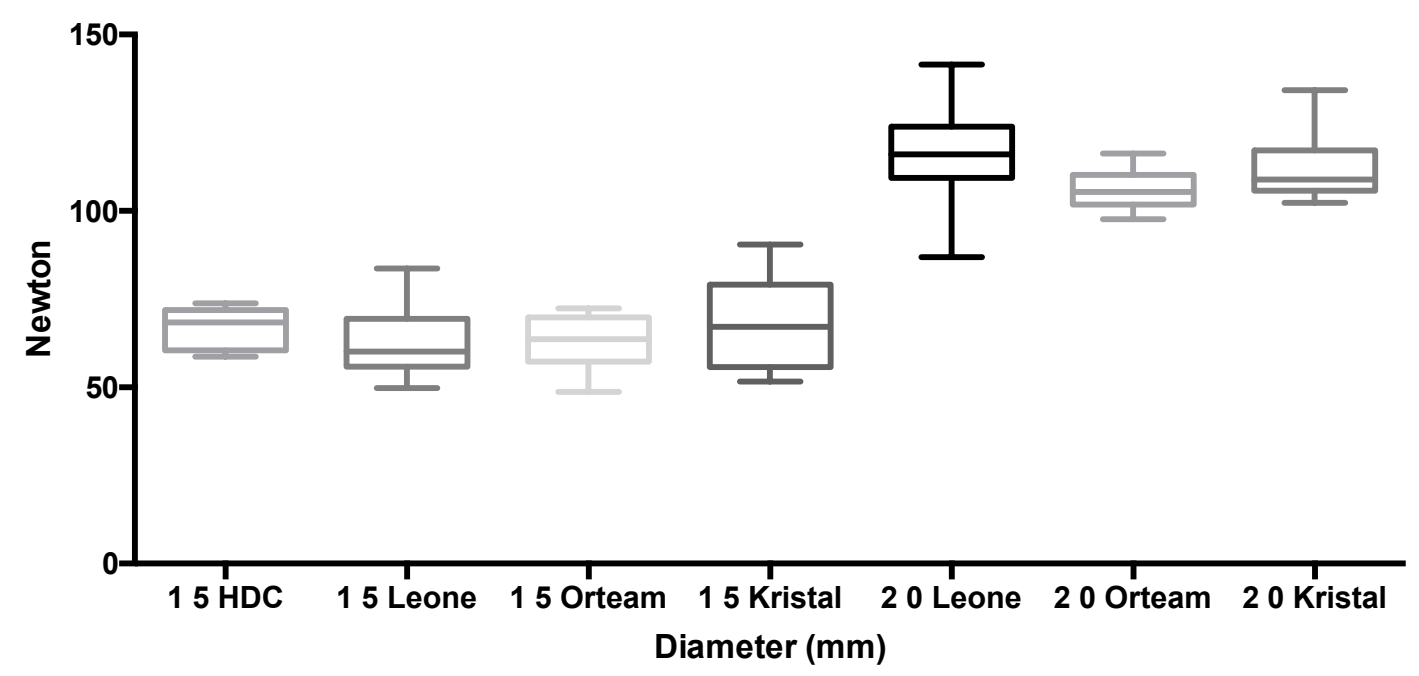

Figure 4. Box plot of groups tested at $0.2 \mathrm{~mm}$ deflection $(\mathrm{N})$.



Figure 5. Box plot of groups tested at maximum load before fracture (N).

No significant differences were reported between titanium and stainless steel screws with the same diameter $(P>0.05)$.

Linear regressions (Figure 6) showed a significant effect of miniscrew diameter on force values recorded at $0.1 \mathrm{~mm}(P<0.0001)$ and $0.2 \mathrm{~mm}(P<0.0001)$ deflections and at maximum load $(P<0.001)$. 


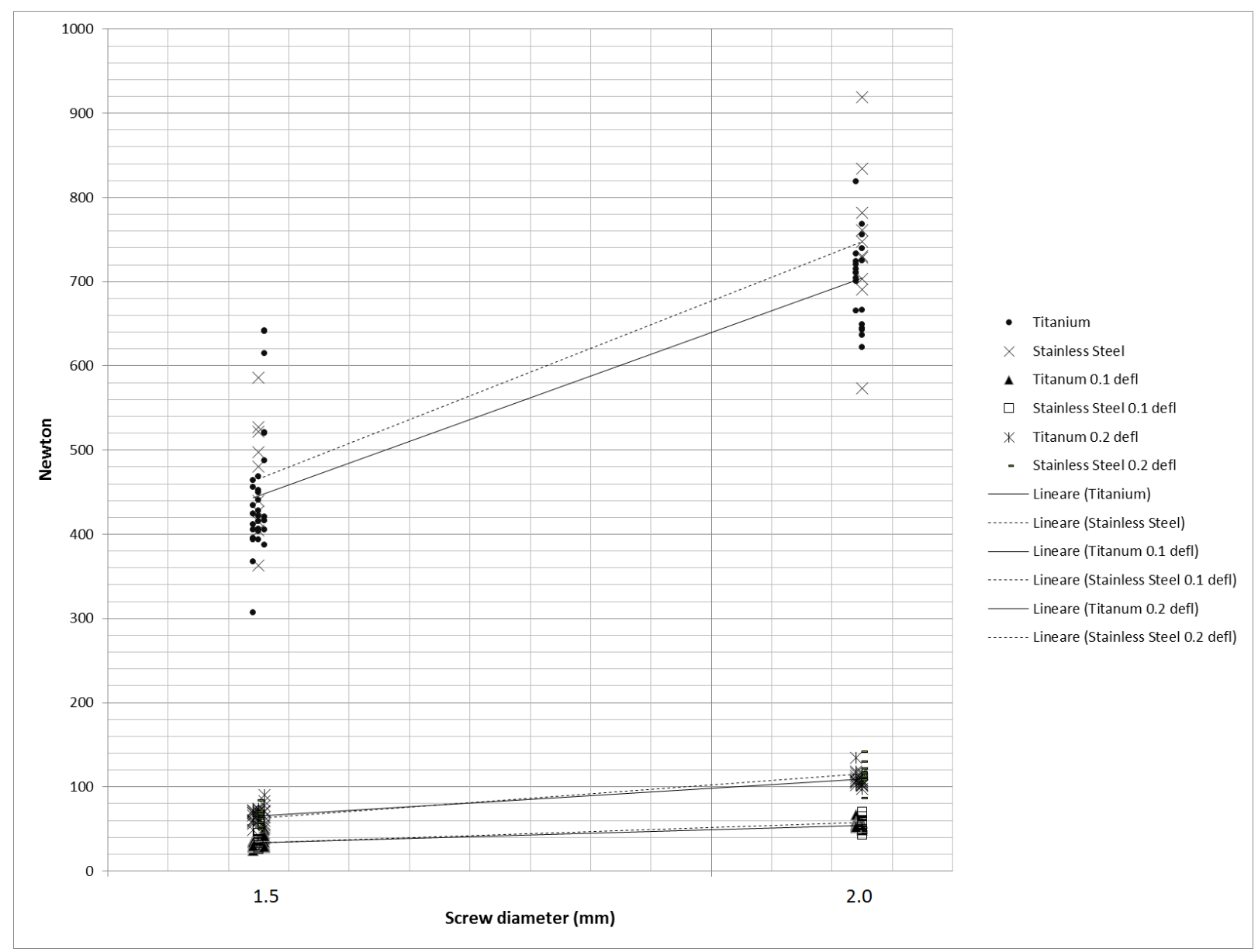

Figure 6. Linear regressions of fracture load values $(\mathrm{N})$ plotted against to the diameter of the collar of the miniscrews in the three different testing conditions $(0.1 \mathrm{~mm}$ deflection, $0.2 \mathrm{~mm}$ deflection and maximum load before fracture).

\section{Discussion}

The null hypothesis of the present report has been rejected. $2.0 \mathrm{~mm}$ diameter miniscrews showed significantly higher bending and fracture loads than $1.5 \mathrm{~mm}$ diameter TADs. Previous studies investigated the clinical reliability of orthodontic miniscrews, showing that TADs are effective for skeletal anchorage in orthodontics, with a high success rate (about $80 \%-90 \%$ ) $[27,28]$. Previous Authors showed that, if miniscrew failure is the most frequent drawback, the screw fracture is the most unwanted complication during TAD employment [15]. In fact, a broken miniscrew has to be removed from bone, with an intervention that is not easy nor always successful. For these reasons, sometimes broken mini implants are left in the bone [15]. When miniscrews are used for orthodontic anchorage, the fracture risk is relatively low (about 1\%) [29]. However when mini implants are used for non-conventional orthopedic applications, fracture risk could increase. TADs have been reported to be used for mandibular fractures management [10]. Other Authors proposed the use of these devices in miniscrew-supported temporary pontics [12]. Moreover, the use of orthodontic miniscrews has been proposed also in combination with maxillary expansion appliances [11]. In all these cases, the mini implants are subjected to higher tangential forces if compared with conventional orthodontic anchorage uses. Therefore, in the present report, miniscrews have been tested on air for tangential load, as this vector of force is the same to which TADs are subjected when mini implants are employed for unconventional orthopaedic uses [16]. Moreover, during these applications, forces generated at screw collar are significantly higher than strengths generated when the screw is used for conventional orthodontic anchorage, therefore higher resistance to plastic deformation and fracture is needed [15]. The collar region can be considered the "locus minoris resistentiæ" of the 
whole screw, and this is the main reason for which the bending and fracture force has been applied in this specific point of the mini implant in the present investigation.

Orthodontic mini implants have been previously tested both in vitro $[13,14,30,31]$ and in vivo [3-8]. However, no studies evaluated in air bending and fracture loads, therefore the results of the present investigation are not directly comparable with existing Literature. On the other hand, many Authors studied insertion and removal torque loads, showing a significant effect of screw diameter. In fact, lowest forces were recorded with small-diameter miniscrews, whereas higher values were found with higher diameter mini implants [32]. This is in agreement with the present report, both when evaluating bending and fracture loads after shear strength application.

Miniscrews are marketed with different lengths and diameters. During clinical practice long screws $(\geq 8 \mathrm{~mm})$ present significantly higher success rates than the rates obtained with short ones $(<$ $8 \mathrm{~mm}$ ) [31]. However, it has been demonstrated that as the length of the miniscrew in contact with the bone is increased, the amounts and patterns of stress distribution in the cortical bone and the miniscrew do not change significantly [30]. For this reason, the miniscrew length has not been considered as a variable in the present investigation.

In our report, all the screws evaluated were new. No tests have been conducted on retrieved mini-implants. In dentistry, some materials are reused after disinfection and sterilization procedures. In vitro [33] and in vivo [34] studies demonstrated reliability of many reconditioned orthodontic devices. In addition, miniscrews $[35,36]$ has been tested after recycling, showing that morphological changes mainly occurred at the screw tip. The cortical bone penetration success rate of recycled screws has been reported to be lower than that of unused screws. On the other hand, no significant difference in bone-implant contact ratio has been found between new and used miniscrews [36]. Moreover, also fracture torque has been showed to be not influenced by recycling protocols [35]. However, future reports are needed in order to test bending and fracture loads for retrieved miniscrews before suggesting clinical use.

Orthodontic mini implants are marketed both made with titanium or stainless steel. No significant differences between the two materials have been found regarding the percent of bone-toimplant contact or the static and dynamic bone parameters [37]. However, there are no studies that compared mechanical behavior of miniscrews of different materials. In our study, both titanium and stainless steel miniscrews were considered. No significant differences were recorded in bending and fracture loads between titanium and stainless steel TADs for both diameters tested $(1.5 \mathrm{~mm}$ and 2.0 $\mathrm{mm}$ ). Alpha-beta titanium alloy tested in our report (Ti-6Al-4V - UNS designation R56400) presents low weight, high strength and corrosion resistance, and it is used for many dental applications. Moreover, titanium biomedical devices shows high biocompatibility and no cytotoxic effects [38]. In addition, stainless steel miniscrews have been tested for biocompatibility, showing no cytotoxic effects also at low pH values [17]. However, during orthodontic treatment, brackets, bands, arches and auxiliaries cause cell alterations of variable intensity [39]. No cytotoxic effect has been reported, but metals [40], nickel [41] and chromium [42] release from orthodontic appliances has been demonstrated, even if nowadays there is no evidence of toxic effects for any orthodontic metal-based device. Of course, "the absence of evidence is not an evidence of absence" and future studies on the topic are always welcomed [43]. Anyway, the short-term use of orthodontic devices, allow a safe management of metallic materials, thus including stainless steel and titanium miniscrews tested in the present report [38].

\section{Conclusions}

Within the limitations of this in vitro study, the present report demonstrated that:

- $2.0 \mathrm{~mm}$ diameter miniscrews showed significantly higher bending and fracture forces than 1.5 mm diameter TADs.

- No significant differences were reported between titanium and stainless steel screws with the same diameter.

Based on these results, when placing a miniscrew for non-conventional TAD applications or when maximum bending and fracture resistance is needed, and clinicians aim to reduce risk of 
unwanted fracture due to tangential forces, a larger diameter is safer than thinner diameter, regardless the mini implant material.

Funding: This research received no external funding.

Acknowledgements: We thank HDC, Leone, Orteam and Kristal for providing the materials tested in the present study.

Conflicts of Interest: The authors declare that there is no conflict of interest regarding the publication of this paper.

\section{References}

1. Montasser MA, Keilig L, El-Bialy T, Reimann S, Jäger A, Bourauel C. Effect of archwire cross-section changes on force levels during complex tooth alignment with conventional and self-ligating brackets. Am J Orthod Dentofacial Orthop. 2015 Apr;147(4 Suppl):S101-8.

2. Leung MT, Lee $\mathrm{TC}$, Rabie $\mathrm{AB}$, Wong RW. Use of miniscrews and miniplates in orthodontics. J Oral Maxillofac Surg. 2008 Jul;66(7):1461-6.

3. Mesko ME, Skupien JA, Valentini F, Pereira-Cenci T. Can we close large prosthetic space with orthodontics? Int J Orthod Milwaukee. 2013 Fall;24(3):41-4.

4. Dahiya A, Singh G. Incisor Intrusion with a Miniscrew-Anchored Segmental Utility Arch. J Clin Orthod. 2016 Jun;50(6):375-6.

5. Rodriguez Y Baena R, Lupi MS, Ceriana G, Sfondrini MF, Scribante A. Extrusion of severely impacted mandibular first molar using partial orthodontics and temporary anchorage miniscrews. Eur J Paediatr Dent. 2016 Dec;17(4):310-314.

6. Chung K, Kim SH, Kook Y. C-orthodontic microimplant for distalization of mandibular dentition in Class III correction. Angle Orthod. 2005 Jan;75(1):119-28.

7. Wang SH, Shih YH, Liaw JJ. Correction of Unilateral Complete Buccal Crossbite with Miniscrew Anchorage. J Clin Orthod. 2016 Aug;50(8):493-502.

8. Yamada K, Kuroda S, Deguchi T, Takano-Yamamoto T, Yamashiro T. Distal movement of maxillary molars using miniscrew anchorage in the buccal interradicular region. Angle Orthod. 2009 Jan;79(1):78-84.

9. Kircelli BH, Pektaş ZO, Uçkan S. Orthopedic protraction with skeletal anchorage in a patient with maxillary hypoplasia and hypodontia. Angle Orthod. 2006 Jan;76(1):156-63.

10. Pires MS, Reinhardt LC, Antonello G de M, Torres do Couto R. Use of orthodontic mini-implants for maxillomandibular fixation in mandibular fracture. Craniomaxillofac Trauma Reconstr. 2011 Dec;4(4):2136.

11. Suzuki H, Moon W, Previdente LH, Suzuki SS, Garcez AS, Consolaro A. Miniscrew-assisted rapid palatal expander (MARPE): the quest for pure orthopedic movement. Dental Press J Orthod. 2016 Jul-Aug;21(4):1723.

12. Wilmes B, Nienkemper M, Renger S, Drescher D. Mini-implant-supported temporary pontics. J Clin Orthod. 2014 Jul;48(7):422-9.

13. Morarend C, Qian F, Marshall SD, Southard KA, Grosland NM, Morgan TA, McManus M, Southard TE. Effect of screw diameter on orthodontic skeletal anchorage. Am J Orthod Dentofacial Orthop. 2009 Aug;136(2):224-9.

14. Lim SA, Cha JY, Hwang CJ. Insertion torque of orthodontic miniscrews according to changes in shape, diameter and length. Angle Orthod. 2008 Mar;78(2):234-40. doi: 10.2319/121206-507.1.

15. Kuroda S, Tanaka E. Risks and complications of miniscrew anchorage in clinical orthodontics. Japanese Dental Science Review. 2014;50:79-85.

16. Mizrahi E. The Use of Miniscrews in Orthodontics: a Review of Selected Clinical Applications. Prim Dent J. 2016 Nov 1;5(4):20-27.

17. Galeotti A, Uomo R, Spagnuolo G, Paduano S, Cimino R, Valletta R, D'Antò V. Effect of pH on in vitro biocompatibility of orthodontic miniscrew implants. Prog Orthod. 2013 Jul 1;14:15. 
18. Seifi M, Matini NS. Evaluation of primary stability of innovated orthodontic miniscrew system (STS): An ex-vivo study. J Clin Exp Dent. 2016 Jul 1;8(3):e255-9.

19. Ahmed VK, Krishnaswamy NR, Thavarajah R. Miniscrew implant fracture and effects of such retained tip on dentin-pulp complex: a histological report. Dent Traumatol. 2016 Apr;32(2):161-5.

20. Reicheneder C, Rottner K, Bokan I, Mai R, Lauer G, Richter G, Gedrange T, Proff P. Mechanical loading of orthodontic miniscrews - significance and problems: an experimental study. Biomed Tech (Berl). 2008 Oct;53(5):242-5.

21. Smith A, Hosein YK, Dunning CE, Tassi A. Fracture resistance of commonly used self-drilling orthodontic mini-implants. Angle Orthod. 2015 Jan;85(1):26-32

22. Bayani S, Masoomi F, Aghaabbasi S, Farsinejad A. Evaluation of the Effect of Platelet-Released Growth Factor and Immediate Orthodontic Loading on the Removal Torque of Miniscrews. Int J Oral Maxillofac Implants. 2016 Mar-Apr;31(2):471-7.

23. Cacciafesta V, Sfondrini MF, Lena A, Scribante A, Vallittu PK, Lassila LV. Force levels of fiber-reinforced composites and orthodontic stainless steel wires: a 3-point bending test. Am J Orthod Dentofacial Orthop. 2008 Mar;133(3):410-3.

24. Sfondrini MF, Massironi S, Pieraccini G, Scribante A, Vallittu PK, Lassila LV, Gandini P. Flexural strengths of conventional and nanofilled fiber-reinforced composites: a three-point bending test. Dent Traumatol. 2014 Feb;30(1):32-5.

25. Cacciafesta V, Sfondrini MF, Lena A, Scribante A, Vallittu PK, Lassila LV. Flexural strengths of fiberreinforced composites polymerized with conventional light-curing and additional postcuring. Am J Orthod Dentofacial Orthop. 2007 Oct;132(4):524-7.

26. Scribante A, Massironi S, Pieraccini G, Vallittu P, Lassila L, Sfondrini MF, Gandini P. Effects of nanofillers on mechanical properties of fiber-reinforced composites polymerized with light-curing and additional postcuring. J Appl Biomater Funct Mater. 2015 Oct 16;13(3):e296-9.

27. Yi Lin S, Mimi Y, Ming Tak C, Kelvin Weng Chiong F, Hung Chew W. A study of success rate of miniscrew implants as temporary anchorage devices in Singapore. Int J Dent. 2015;2015:294670.

28. Melo AC, Andrighetto AR, Hirt SD, Bongiolo AL, Silva SU, Silva MA. Risk factors associated with the failure of miniscrews - A ten-year cross sectional study. Braz Oral Res. 2016 Oct 24;30(1):e124

29. Jing Z, Wu Y, Jiang W, Zhao L, Jing D, Zhang N, Cao X, Xu Z, Zhao Z. Factors Affecting the Clinical Success Rate of Miniscrew Implants for Orthodontic Treatment. Int J Oral Maxillofac Implants. 2016 JulAug;31(4):835-41

30. Ajami S, Mina A, Nabavizadeh SA. Stress distributions of a bracket type orthodontic miniscrew and the surrounding bone under moment loadings: Three-dimensional finite element analysis. J Orthod Sci. 2016 Apr-Jun;5(2):64-9. doi: 10.4103/2278-0203.179416.

31. Hong SB, Kusnoto B, Kim EJ, BeGole EA, Hwang HS, Lim HJ. Prognostic factors associated with the success rates of posterior orthodontic miniscrew implants: A subgroup meta-analysis. Korean J Orthod. 2016 Mar;46(2):111-26. doi: 10.4041/kjod.2016.46.2.111. Epub 2016 Mar 18.

32. Wilmes B, Panayotidis A, Drescher D. Fracture resistance of orthodontic mini-implants: a biomechanical in vitro study. Eur J Orthod. 2011 Aug;33(4):396-401.

33. Sfondrini MF, Xheka E, Scribante A, Gandini P, Sfondrini G. Reconditioning of self-ligating brackets. Angle Orthod. 2012 Jan;82(1):158-64. doi: 10.2319/033011-227.1. Epub 2011 Aug 1.

34. Cacciafesta V, Sfondrini MF, Melsen B, Scribante A. A 12 month clinical study of bond failures of recycled versus new stainless steel orthodontic brackets. Eur J Orthod. 2004 Aug;26(4):449-54.

35. Estelita S, Janson G, Chiqueto K, Ferreira ES. Effect of recycling protocol on mechanical strength of used mini-implants. Int J Dent. 2014;2014:424923. doi: 10.1155/2014/424923. Epub 2014 Jul 17.

36. Yun SD, Choi SH, Cha JY, Yu HS, Kim KM, Kim J, Hwang CJ. Effects of recycling on the biomechanical characteristics of retrieved orthodontic miniscrews. Korean J Orthod. 2017 Jul;47(4):238-247. doi: 10.4041/kjod.2017.47.4.238. Epub 2017 May 26.

37. Gritsch K, Laroche N, Bonnet JM, Exbrayat P, Morgon L, Rabilloud M, Grosgogeat B. In vivo evaluation of immediately loaded stainless steel and titanium orthodontic screws in a growing bone. PLoS One. 2013 Oct 4;8(10):e76223.

38. Tuomi JT, Björkstrand RV, Pernu ML, Salmi MV, Huotilainen EI, Wolff JE, Vallittu PK, Mäkitie AA. In vitro cytotoxicity and surface topography evaluation of additive manufacturing titanium implant materials. J Mater Sci Mater Med. 2017 Mar;28(3):53. 
39. Sodor A, Ogodescu AS, Petreuş T, Şişu AM, Zetu IN. Assessment of orthodontic biomaterials' cytotoxicity: an in vitro study on cell culture. Rom J Morphol Embryol. 2015;56(3):1119-25.

40. Downarowicz P, Mikulewicz M. Trace metal ions release from fixed orthodontic appliances and DNA damage in oral mucosa cells by in vivo studies: A literature review. Adv Clin Exp Med. 2017 Oct;26(7):11551162.

41. Sfondrini MF, Cacciafesta V, Maffia E, Scribante A, Alberti G, Biesuz R, Klersy C. Nickel release from new conventional stainless steel, recycled, and nickel-free orthodontic brackets: An in vitro study. Am J Orthod Dentofacial Orthop. 2010 Jun;137(6):809-15.

42. Sfondrini MF, Cacciafesta V, Maffia E, Massironi S, Scribante A, Alberti G, Biesuz R, Klersy C. Chromium release from new stainless steel, recycled and nickel-free orthodontic brackets. Angle Orthod. 2009 Mar;79(2):361-7.

43. O'Brien K, Sandler J. In the land of no evidence, is the salesman king? Am J Orthod Dentofacial Orthop. 2010 Sep;138(3):247-9.

(C) 2018 by the authors; licensee MDPI, Basel, Switzerland. This article is an open access article distributed under the terms and conditions of the Creative Commons Attribution (CC BY) license (http://creativecommons.org/licenses/by/4.0/). 